\title{
3D Finite Element Simulation of T-Joint Fillet Weld: Effect of Various Welding Sequences on the Residual Stresses and Distortions
}

\author{
Nur Syahroni and Mas Irfan Purbawanto Hidayat
}

Additional information is available at the end of the chapter

http://dx. doi. org/10. 5772/50192

\section{Introduction}

Due to the nature of welding process involving localized heat generation from moving heat source (s), rapid heating in the welded structures, and subsequent rapid cooling, problems such as residual stresses and distortions of welded structures remain great challenges to welding practitioners, designers and modeler. From modeling point of view, it will be very useful if the parameters of interest which contribute to the residual stresses and distortions in various types of welded joint and structure application can be simulated numerically so that welding performance with respect to the various aspects could be assessed and evaluated in an efficient manner (Goldak \& Akhlagi, 2005; Lindgren, 2006; and Zacharia et al., 1995). Thorough consideration and assessment of the welding quality could then also be performed in earlier stage in a virtual environment. Moreover, dimensional inaccuracies due to the welding deformation giving rise problems in subsequent assembly and fabrication processes could also be predicted along with the necessary justification needed.

In recent years, various aspects and interests in the numerical modeling of welding residual stresses and distortions, mostly using finite element method, have been elaborated by researchers. Teng \& Lin (1998) predicted the residual stresses during one-pass arc welding in steel plate using ANSYS software and discussed the effects of travel speed, specimen size, external mechanical constraints and preheating on the residual stresses. Tsai et al. (1999) studied the distortion mechanisms and the effect of welding sequence on panel distortion and utilized 2D finite element model. Residual stresses and distortions in T-joint fillet welds with the effects of flange thickness, welding penetration depth and restraint condition of welding was simulated by Teng et al. (2001) using thermal elasto-plastic finite element 
techniques. Further, effect of welding sequences on residual stresses of multi-pass buttwelds and circular patch welds was also investigated by Teng et al. (2003). Moreover, Chang \& Lee (2009) performed the finite element analysis of the residual stresses in T-joint fillet welds made of similar and dissimilar steels.

The present study extends the previous work of Teng et al. (2001) and focuses on numerical simulation of welding sequence effect on temperature distribution, residual stresses and distortions of T-joint fillet welds. Several welding sequences were considered and the resulted distribution of welding temperature, longitudinal and transverse residual stresses and angular distortions were simulated utilizing three dimensional finite element models. Four welding sequences considered were one direction welding, contrary direction welding, welding from centre of one side and welding from centres of two sides. Further, a welding sequence producing the smallest residual stress, distortion as well as distortion difference between both flanges was then investigated. The numerical simulation was done in ANSYS environment.

\section{Theoretical background}

Basic mechanisms of welding residual stress and distortion together with the finite element formulations used in the $3 \mathrm{D}$ numerical simulation are described in the following subsections.

\subsection{Basic mechanism of welding residual stresses}

Complex heating and cooling cycles encountered in weldments lead to transient thermal stresses and incompatible strains produced in region near the weld. After heat cycles of welding diminished, the incompatible strains remain and provoking locked stresses or frequently termed as welding residual stresses. In general, term of residual stress deal with those remaining stress in a structure even though no external load applied (Masubuchi, 1980). Several terms having similar meaning with residual stress were found in some literatures, namely: internal stress, initial stress, inherent stress, reaction stress, lock-in stress, etc. In term of welding process, residual stress are the remaining internal stresses after welding and cooling down to room temperature.

There are two basic mechanisms to explain how residual stress produced by welding process, namely: the structural mismatch and the uneven distribution of non-elastic strain composed by plastic and thermal strains.

\subsubsection{Residual stress due to mismatch}

The residual stress mechanism due to mismatch may be simply illustrated in Fig. 1 . Consider three carbon-steel bars of equal length and cross section connected together with two rigid blocks at the ends. The middle bar is heated up to $600^{\circ} \mathrm{C}$ and then cooled to room temperature while no applied heating on the other two bars. Since the expansion of the 


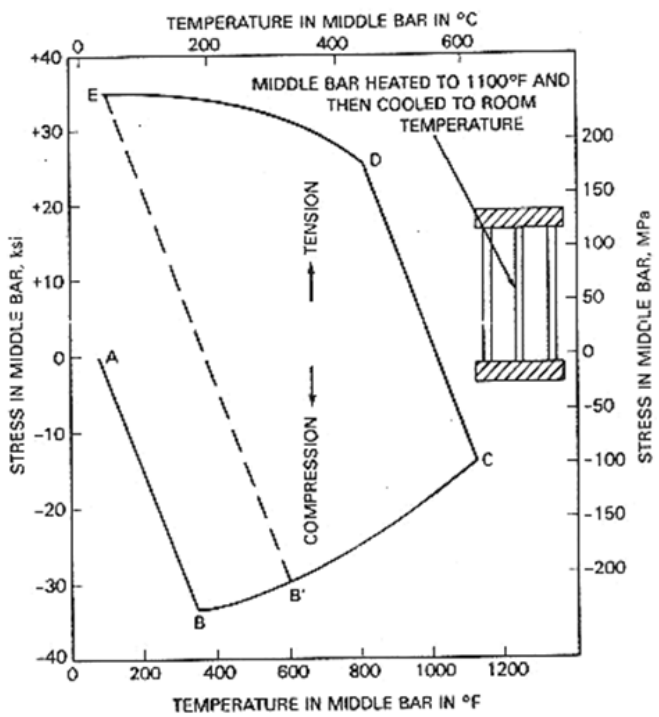

Figure 1. Illustration of residual stress mechanism in welding (source: Masubuchi, 1980)

middle bar is restricted by other bars, compressive stress is encountered at the middle bar and the two side bars are subjected to opposite tensile stress. The compressive stress on middle bar, increases in linear elastic manner when it is heated (AB curve) until the yield stress of material in particular temperature reached, then plastic deformation is encountered which affects in decreasing compressive stress (BC curve). During cooling stage, the stress sign in middle bar is dramatically changed from compressive to tension stress and increases in linear elastic way (CD curve) up to the yield stress at point D. Then, non-linear plastic behaviour takes place (DE curve) in room temperature resulting in a tensile residual stress in the middle bar and contrary a compressive residual stress in both side bars which are equal to one-half of tensile stress in the middle bar.

\subsubsection{Residual stress due to uneven distribution of non-elastic strains}

When a metal bar is subjected to a uniform heat, it produces a uniform expansion lead to no thermal stresses. However, when it is subjected to non-uniform heat as the case of welding, thermal stresses and strains will be formed. Residual stress field in plane stress condition $\left(\sigma_{z}\right.$ $=0$ ) can be expressed by the following formulas:

- $\quad$ Elastic and plastic strains:

$$
\begin{aligned}
& \varepsilon_{x}=\varepsilon_{x}{ }^{\prime}+\varepsilon_{x}{ }^{\prime \prime}, \\
& \varepsilon_{y}=\varepsilon_{y}{ }^{\prime}+\varepsilon_{y}{ }^{\prime}, \\
& \gamma_{x y}=\gamma_{x y}{ }^{\prime}+\gamma_{x y}{ }^{\prime \prime} .
\end{aligned}
$$


where:

$\varepsilon_{x}, \varepsilon_{y}, \gamma_{x y}$ is components of the total strain,

$\varepsilon_{x}^{\prime}, \varepsilon_{y}^{\prime}, \gamma_{x y}^{\prime}$ is components of the elastic strains,

$\varepsilon_{x}^{\prime \prime}, \varepsilon_{y}^{\prime \prime}, \gamma_{x y}^{\prime \prime}$ is components of the plastic strains.

- Relationships of stress vs. elastic strain by Hooke's law:

$$
\begin{aligned}
& \varepsilon_{x}^{\prime}=\frac{1}{E}\left(\sigma_{x}-v \sigma_{y}\right), \\
& \varepsilon_{y}^{\prime}=\frac{1}{E}\left(\sigma_{y}-v \sigma_{x}\right), \\
& \gamma_{x y}{ }^{\prime}=\frac{1}{G} \tau_{x y} .
\end{aligned}
$$

- The stress must satisfy the equilibrium conditions:

$$
\begin{aligned}
& \frac{\partial \sigma_{x}}{\partial x}+\frac{\partial \tau_{x y}}{\partial y}=0 \\
& \frac{\partial \tau_{x y}}{\partial x}+\frac{\partial \sigma_{y}}{\partial y}=0 .
\end{aligned}
$$

- The total strain must satisfy the conditions of compatibility:

$$
\left[\frac{\partial^{2} \varepsilon_{x}^{\prime}}{\partial y^{2}}+\frac{\partial^{2} \varepsilon_{y}^{\prime}}{\partial x^{2}}-\frac{\partial^{2} \gamma_{x y}^{\prime}}{\partial x \partial y}\right]+\left[\frac{\partial^{2} \varepsilon_{x}^{\prime \prime}}{\partial y^{2}}+\frac{\partial^{2} \varepsilon_{y}^{\prime \prime}}{\partial x^{2}}-\frac{\partial^{2} \gamma_{x y}^{\prime \prime}}{\partial x \partial y}\right]=0
$$

The second term of Eq. (4), which is called the incompatibility term, $R$, is determined by plastic strain. When the value of $R$ is not zero, thus residual stresses will exist in the weld joint.

$$
R=-\left[\frac{\partial^{2} \varepsilon_{x}^{\prime \prime}}{\partial y^{2}}+\frac{\partial^{2} \varepsilon_{y}^{\prime \prime}}{\partial x^{2}}-\frac{\partial^{2} \gamma_{x y}^{\prime \prime}}{\partial x \partial y}\right]
$$

More realistic illustration of the residual stress mechanisms during welding in typical plate joints is shown in Fig. 2. Welding bead is made along $x$-axis on the plate. Welding is carried out by moving the welding arc at speed $v$, and presently it is located at the origin $\mathrm{O}$, as illustrated in Fig. 2a. Temperature distributions along particular points at weldline are shown in Fig. 2b, while stress resulted in the respect points are shown in Fig. 2c.

Along point A-A which is located ahead of the welding arc is not affected by heat yet. Section B-B experiences highest heat distribution (Fig. 2b. 2) which results in compressive stresses at just besides of weldline and surrounded by opposite tensile stresses in the side far 


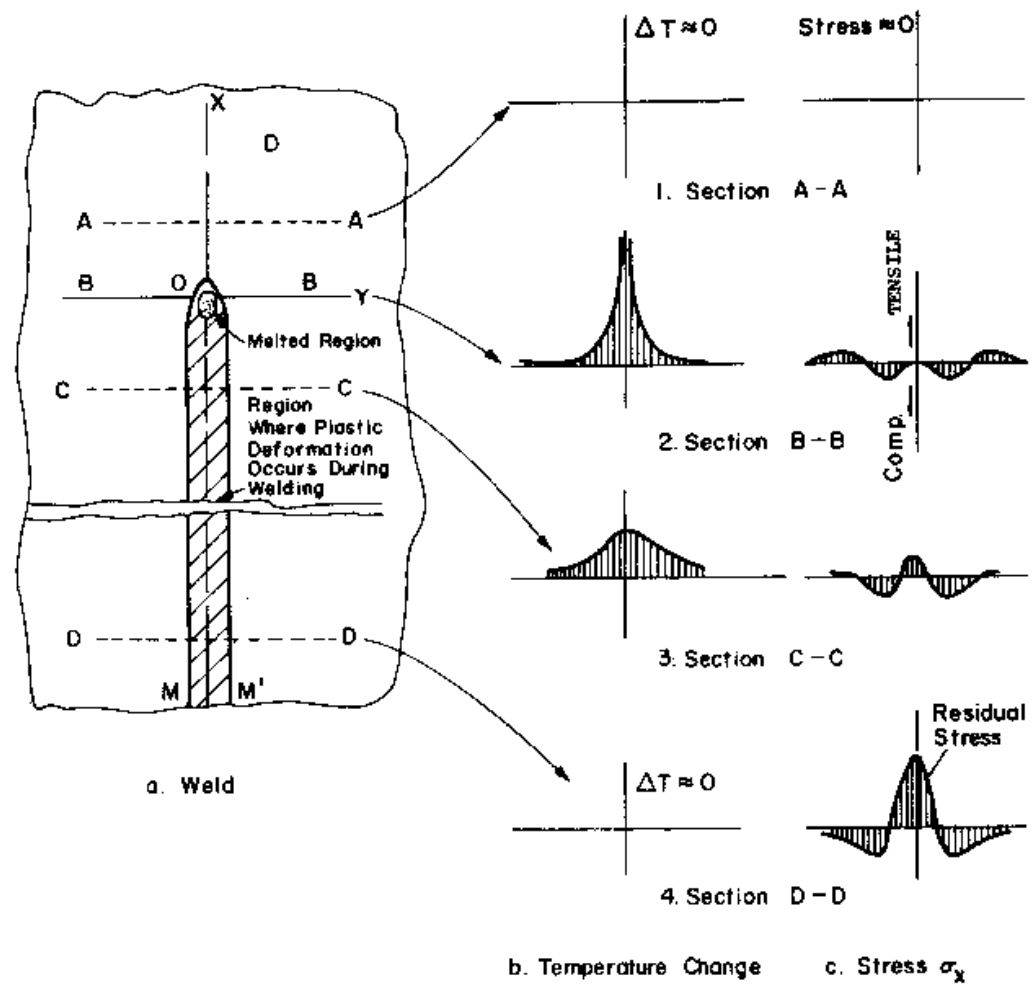

Figure 2. Schematic illustrations of heat cycles in welding and residual stress results (source: Masubuchi, 1980)

away from weld line, whilst at weldment has zero stress due to metal melted (Fig. 2c. 2). Section C-C which is located at some distance behind welding arc is subjected to moderate heat (Fig. 2b. 3) due to cooling stage started in this section in which the condition at this section is similar to those CD curve in Fig. 1. Some distance far away from heat source, cooling down into room temperature is achieved which results in residual stresses in similar way to those in the end of DE curve in Fig. 1.

Furthermore, typical distributions of butt joints in plate are presented in Fig. 3. Components of residual stress are categorized into transverse and longitudinal, designated as $\sigma_{\mathrm{x}}$ and

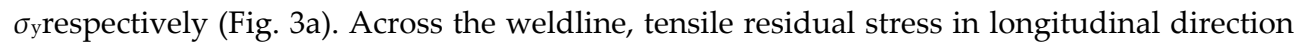
parallel to the weldline is found in the weldment region and compressive residual stresses occur in the others region away from weldline (Fig. 3b). Transverse residual stresses distributions along weldline are typically compressive part in the ends of plate, otherwise are tensile part with magnitude of stresses is lower than longitudinal residual stress (Fig. 3c). Masubuchi \& Martin (Masubuchi, 1980) have developed the distribution of longitudinal residual stress $\sigma_{\mathrm{x}}$ which can be estimated as follows: 


$$
\sigma_{x}=\sigma_{m}\left\{1-\left(\frac{y}{b}\right)^{2}\right\} e^{-\frac{1}{2}(y / b)^{2}}
$$
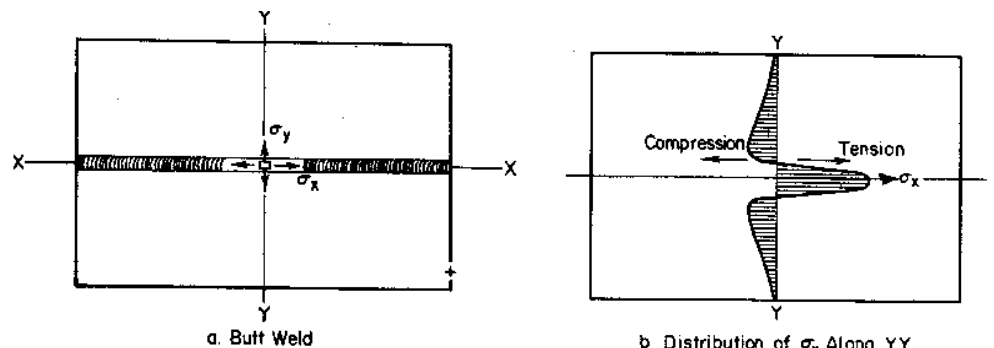

b. Distribution of $\sigma_{\mathrm{X}}$ Along $Y Y$

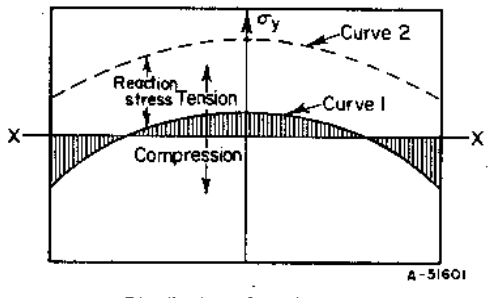

c Distribution of $\sigma_{\mathrm{y}}$ Along $\mathrm{x} x$

Figure 3. Typical distributions of residual stress in plate butt joints (source: Masubuchi, 1980)

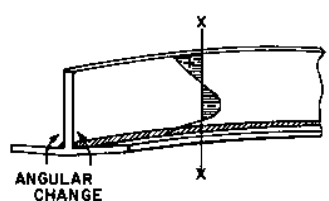

a. RESIOUAL STRESSES AND DISTORTION OF A WELDED T-SHAPE

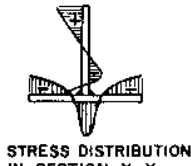

iN SECTION $\mathbf{x}-\mathbf{x}$

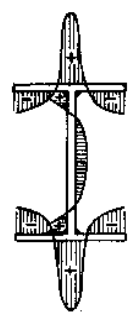

b. RESIDUAL STRESSES IN AN H-SHAPE

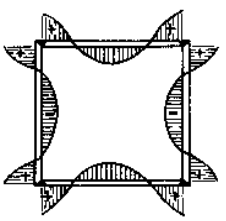

C. RESIDUAL STRESSES IN A BOX SHAPE

Figure 4. Typical residual stresses in welded structural profiles (source: Masubuchi, 1980)

Fig. 4a shows residual stresses produced in welded T-shape and the residual stresses distributions. As can be further seen, high tensile residual stresses parallel to the axis are produced in areas near the weld in section away from the end of the column. In addition, stresses in the flange are tensile near the weld and compressive away from the weld. The tensile stresses near the upper edge of web are due to longitudinal bending distortion caused by longitudinal shrinkage. Furthermore, Figs. $4 \mathrm{~b}$ and $4 \mathrm{c}$ show the typical distribution of residual stress in an H-shape and a box shape, respectively, particularly the distributions of residual stresses parallel to the weld line, in which the residual stresses are tensile in areas near the welds and compressive in area away from the welds. 


\subsection{Welding distortions}

Distortion is closely related to the amount of residual stress and the degree of joint restraint during welding process. The correlation between distortion and residual stress is illustrated in Fig. 5. As rule of thumb, the welded joint with lower degree of restraint has an advantage due to less residual stress but it tends to get higher distortion. Conversely, the welded joint with higher degree of restraint has less distortion but it will further result in higher residual stress.

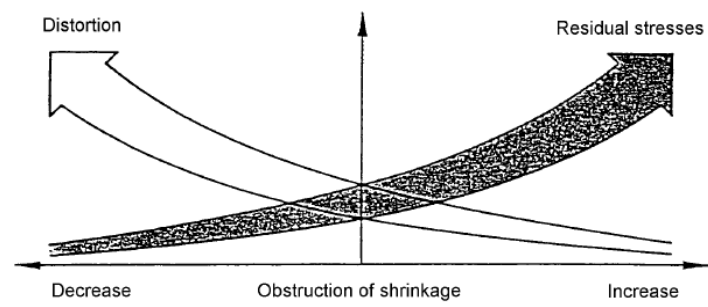

Figure 5. Welding residual stress and distortion correlation (source: Bette, 1999)

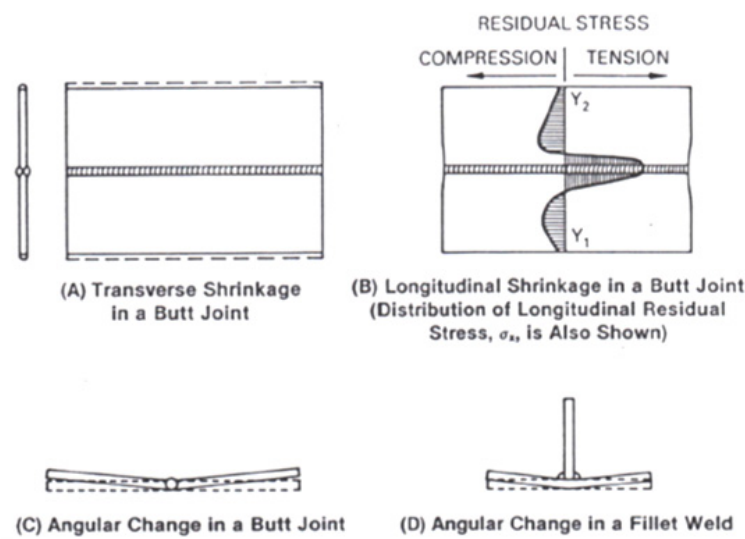

Figure 6. Three basic dimensional changes during welding (source: AWS Welding Handbook, 1987)

There are three basic dimensional changes during welding process with which we can easily understand the mechanism of distortion, namely:

- Transverse shrinkage, Fig. 6A, is a distortion perpendicular to the weld line

- Longitudinal shrinkage, Fig. 6B, is a distortion parallel to the weld line

- Angular change, in butt joint and $\mathrm{T}$ joint fillet weld, as shown in Figs. 6C and 6D, respectively, deformation in rotation form around the weld. It happens when the transverse shrinkage is not uniform in the thickness direction

In actual structures, the welding distortions are frequently more complex than these basic distortions or taking place with some conditions. For examples, pure transverse or longitudinal shrinkage will only take place when the following conditions apply, i. e. 
thickness of member is large enough and centre of gravity of the welds is in line with the neutral axis of the components. When it is not the case, the rotational deformations such as the angular, bending and buckling distortion may be happened.

The empirical formula to estimate the quantity of transverse shrinkage of carbon and low alloy steel butt welds can be found in American Welding Society (AWS) Welding Handbook (1987) as follows:

$$
S=0.2 \frac{A_{w}}{t} 0.05 d
$$

where:

$S$ is transverse shrinkage, in,

$A_{\mathrm{w}}$ is cross sectional area of weld, in ${ }^{2}$,

$t$ is thickness of plate, in,

$d$ is root opening, in.

In fillet weld, the amount of transverse shrinkage is less than that happened in butt weld. The transverse shrinkage in fillet weld may be expressed by the following formulas found in AWS Welding Handbook (1987):

- $\quad$ For T-joint with two continuous fillet welds:

$$
S=C_{1}\left(\frac{D_{f}}{t_{b}}\right) .
$$

where:

$S$ is transverse shrinkage, in. or $\mathrm{mm}$,

$D_{\mathrm{f}}$ is fillet leg length, in. or $\mathrm{mm}$,

$t$ is bottom plate thickness, in. or $\mathrm{mm}$,

$C_{1}$ is 0.04 or 1.02 when using unit in. or $\mathrm{mm}$, respectively.

- For lap joint with two fillet welds (the thickness of two plates are equal):

$$
S=C_{2}\left(\frac{D_{f}}{t}\right) .
$$

where:

$S$ is transverse shrinkage, in. or $\mathrm{mm}$,

$D_{\mathrm{f}}$ is fillet leg length, in. or $\mathrm{mm}$,

$t$ is plate thickness, in. or $\mathrm{mm}$,

$C_{2}$ is 0.06 or 1.52 when using unit in. or $\mathrm{mm}$, respectively.

Compared to transverse shrinkage, the quantity of longitudinal shrinkage for butt joint is much less, approximately 1/1000 of the weld length. King, 1944 (as cited in AWS Welding 
Handbook, 1987) proposed a formula to estimate the longitudinal shrinkage of butt joint as follows:

$$
\Delta L=\frac{C_{3} I L}{t} 10^{-7}
$$

where:

$\Delta L$ is longitudinal shrinkage, in. or $\mathrm{mm}$,

I is welding current, A,

$L$ isweld length, in. or $\mathrm{mm}$,

$t$ is plate thickness, in. or $\mathrm{mm}$,

$C_{1}$ is 12 or 305 when using unit in. or $\mathrm{mm}$, respectively.

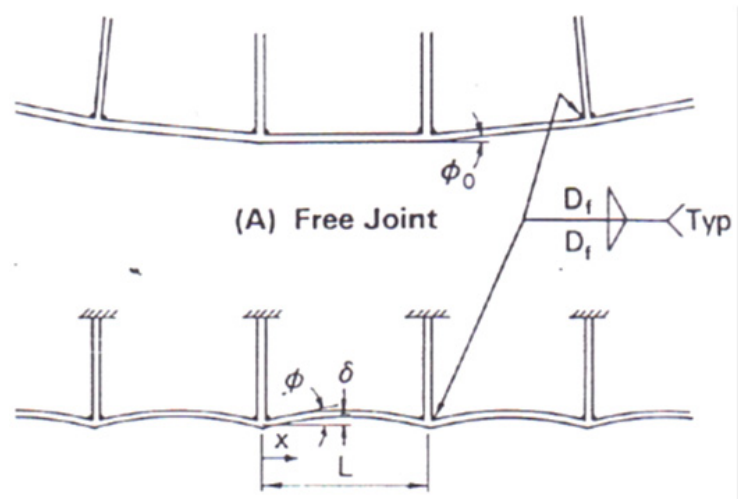

(B) Restrained Joint

Figure 7. Angular change in T-joint fillet weld, (A) free restrained stiffeners, (B) restrained stiffeners

The primary source of angular change is due to non-uniform of transverse shrinkage in thickness direction. Fig. 7a shows angular change of the free restraint T-joint fillet weld. When the stiffeners are prevented from moving, a wavy distortion occurs as can be seen in Fig. 7b. Masubuchi et al., 1956 (as cited in AWS Welding Handbook, 1987) established a relationship between angular change and distortion at fillet weld using a rigid frame analysis in the following expression:

$$
\frac{\delta}{L}=0.25 \phi-\left[\left(\frac{x}{L}\right)-0.5\right]^{2} \phi
$$

where:

$\delta \quad$ is distortion,

$L$ is length of stiffener spacing,

$\phi$ is angular change,

$x$ is distance from centreline of frame to the point at which $\delta$ is measured, Fig. $7 \mathrm{~b}$. 
To summary this section, many factors affect the welding process, thus the produced residual stresses and distortions, such as types of material, types of welded joints, structure thickness, joint restraint, heat input as well as welding sequence, which is the subject of the present study.

\subsection{Thermal and Mechanical Finite Element Equations}

The corresponding finite element equations of thermal and mechanical are obtained by choosing a form of interpolation function representing the variation of the field variables, namely temperature, $T$ and displacement, $U$, within the corresponding finite elements of the structural model and by applying further the weighted-residual or variational argument to the mathematical models. Furthermore, with imposing the boundary and initial conditions, the discritized equations obtained are solved by finite element techniques through which the approximated solution over the finite element model considered could then be obtained.

The thermal finite element equation including boundary condition may be written as follows:

$$
[\mathrm{C}]\{\dot{\mathrm{T}}\}+[\mathrm{K}]\{\mathrm{T}\}=\left\{\mathrm{F}_{\mathrm{T}}\right\},
$$

in which:

$$
\begin{gathered}
{[\mathrm{C}]=\int_{\mathrm{V}} \mathrm{ec}[\mathrm{N}]^{\mathrm{T}}[\mathrm{N}] \mathrm{dV},} \\
{[\mathrm{K}]=\int_{\mathrm{V}} \mathrm{k}[\mathrm{B}]^{\mathrm{T}}[\mathrm{B}] \mathrm{dV}+\int_{\mathrm{S}} \mathrm{h}_{\mathrm{f}}[\mathrm{N}]^{\mathrm{T}}[\mathrm{N}] \mathrm{dS},} \\
\left\{\mathrm{F}_{\mathrm{T}}\right\}=\int_{\mathrm{V}} \mathrm{Q}[\mathrm{N}]^{\mathrm{T}} \mathrm{dV}+\int_{\mathrm{S}} \mathrm{h}_{\mathrm{f}} \mathrm{T}_{\text {ref }}[\mathrm{N}]^{\mathrm{T}} \mathrm{dS} .
\end{gathered}
$$

where:

$\rho \quad$ is the density $\left(\mathrm{kg} / \mathrm{m}^{3}\right)$,

$c$ is the specific heat $(\mathrm{J} / \mathrm{kg} . \mathrm{K})$,

$k$ isthe conductivity $(\mathrm{W} / \mathrm{m} . \mathrm{K})$,

$h_{f}$ is the convective heat transfer coefficient $\left(\mathrm{W} / \mathrm{m}^{2} . \mathrm{K}\right)$,

$Q$ isthe rate of internal heat generation per unit volume $\left(\mathrm{W} / \mathrm{m}^{3}\right)$,

$[\mathrm{N}]$ is the matrix of element shape functions,

[B] is the matrix of shape functions derivative, and

$\{T\}$ is the vector of nodal temperature.

The results of temperature distribution and history obtained from Eq. (12) are then inserted into the mechanical model in the form of thermal load. Incorporating the elasto-plasticity 
analysis, the mechanical finite element equation may be written in the form of incremental as:

$$
{ }^{\mathrm{i}+1}\left[\mathrm{~K}_{1}\right]\{\Delta U\}-{ }^{\mathrm{i}+1}\left[\mathrm{~K}_{2}\right]\{\Delta T\}={ }^{\mathrm{i}+1}\{\mathrm{R}\}-{ }^{i}\{\mathrm{R}\}
$$

in which:

$$
\begin{gathered}
{\left[\mathrm{K}_{1}\right]=\int_{\mathrm{V}}[\mathrm{B}]^{\mathrm{T}}\left[\mathrm{D}^{\mathrm{ep}}\right][\mathrm{B}] \mathrm{dV},} \\
{\left[\mathrm{K}_{2}\right]=\int_{\mathrm{V}}[\mathrm{B}]^{\mathrm{T}}\left[\mathrm{C}^{\mathrm{th}}\right][\mathrm{M}] \mathrm{dV}} \\
\{\mathrm{R}\}=\int_{\mathrm{S}}[\mathrm{N}]^{\mathrm{T}}\{\mathrm{p}\} \mathrm{dS}+\int_{\mathrm{V}}[\mathrm{N}]^{\mathrm{T}}\{\mathrm{f}\} \mathrm{dV}, \\
{\left[\mathrm{D}^{\mathrm{ep}}\right]=\left[\mathrm{D}^{\mathrm{e}}\right]+\left[\mathrm{D}^{\mathrm{p}}\right] .}
\end{gathered}
$$

where:

$\{\Delta U\}$ is the incremental of nodal displacement,

$\{\Delta T\}$ is the incremental of nodal temperature,

$[B]$ is the matrix of strain-displacement,

$\left[D^{e}\right]$ is the matrix of elastic stiffness,

$\left[D^{p}\right]$ is the matrix of plastic stiffness,

$\left[\mathrm{C}^{\text {th }}\right]$ is the matrix of thermal stiffness,

$[\mathrm{M}]$ is the temperature shape function,

$\{p\}$ is the vector of traction or surface force,

$\{f\}$ is the vector of body force, and

$i$ is the current step of analysis.

The vector of nodal displacement at the next step of analysis, ${ }^{i+1}\{U\}$ could be obtained from:

$$
{ }^{\mathrm{i}+1}\{\mathrm{U}\}={ }^{\mathrm{i}}\{U\}+\{\Delta U\} .
$$

Furthermore, the updated condition of stress in the structure could be obtained from the following stress-strain relation:

$$
\begin{gathered}
{ }^{\mathrm{i}+1}\{\sigma\}={ }^{\mathrm{i}}\{\sigma\}+\{\Delta \sigma\}, \\
\{\Delta \sigma\}=\left[\mathrm{D}^{\mathrm{ep}}\right][\mathrm{B}]\{\Delta U\}+\left[\mathrm{C}^{\mathrm{th}}\right][\mathrm{M}]\{\Delta T\} .
\end{gathered}
$$

Commonly, the iterative method of Newton-Raphson is employed in the finite element solver to solve the nonlinear equations. For further treatment, see (Bathe, 1996). Note also 
that from the thermal analysis results, the updated stress and displacement conditions are now obtained.

\section{Material and methods}

In this study, material used for the welding simulation was SAE 1020 with the material properties vary according to the temperature history (Teng et al, 2001 and ASM, 1990). In addition, the welding parameters used in this analysis were as follows: single pass GTAW welding method, welding current, $I=260 \mathrm{~A}$, welding voltage, $V=20 \mathrm{~V}$, and welding speed, $v=5 \mathrm{~mm} / \mathrm{s}$.

\subsection{The variations of welding sequence}

Several welding sequences (WS) were considered in this study and the numerical investigation of the resulted temperature distribution, longitudinal and transverse residual stresses and angular distortions due to the welding sequences was then carried out. Four welding sequences considered were the one direction welding (WS-1), the contrary direction welding (WS-2), the welding from centre of one side (WS-3), and the welding from centres of two sides (WS-4), which are illustrated in Fig. 8.

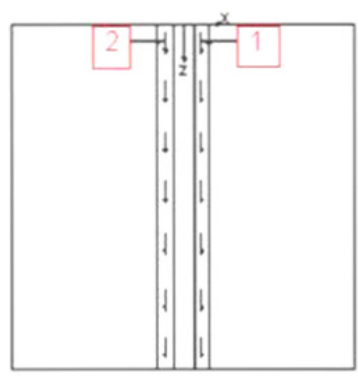

(a)

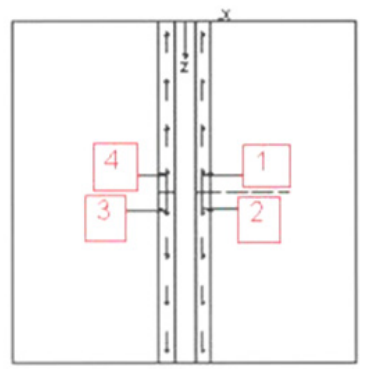

(c)

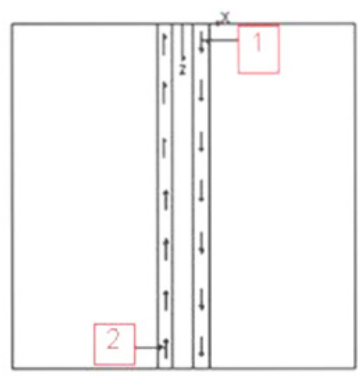

(b)

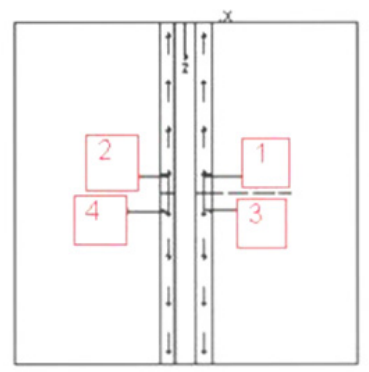

(d)

Figure 8. Variation of welding sequence employed in this study: (a) the one direction welding (WS-1), (b) the contrary direction welding (WS-2), (c) the welding from centre of one side (WS-3), and (d) the welding from centres of two sides (WS-4). 


\section{2. Finite element simulation of welding}

In the present study, a thermal elasto-plastic finite element procedure was employed to simulate the thermo-mechanical response of welding problem. In the procedure, two sequenced thermal and mechanical analyses were carried out independently (uncoupled) to obtain the total or desired response of the welding structure modelled.

A transient thermal analysis of heat conduction was carried out in the first step to obtain temperature distribution histories over the structural model. In the thermal analysis, the welding heat input, $Q_{\mathrm{a}}$ was calculated according to Masubuchi (1980) and the arc efficiency, $\eta_{\mathrm{a}}$ for GTAW was assumed to be 0.60 (Grong, 1994). Also, the values of convective heat transfer coefficient, $h_{\mathrm{f}}$ and reference temperature were taken, respectively, to be $15 \mathrm{~W} / \mathrm{m}^{2}$. K and $25^{\circ} \mathrm{C}(298.15 \mathrm{~K})$.

In the next step, a structural analysis was carried out to now obtain the mechanical response of the structural model, where the temperature history obtained from the first step was employed as a thermal load in the analysis. The material model of elasto-plastic based on the von Mises yield criterion and isotropic strain hardening rule was chosen, in which its response over the history was determined by the temperature-dependent material properties inputted. The boundary condition or constraint on the structural model needs also to be assigned accordingly.

Fig. 9 represents the mesh of T-joint fillet weld employed in this study along with the position of constraint assigned on the finite element model. The total number of nodes and elements utilized for the 3D model were 3654 and 2961, respectively. The analyses were implemented in ANSYS environment utilizing the element type of SOLID70 for the thermal analysis and that of SOLID45 for the structural analysis.

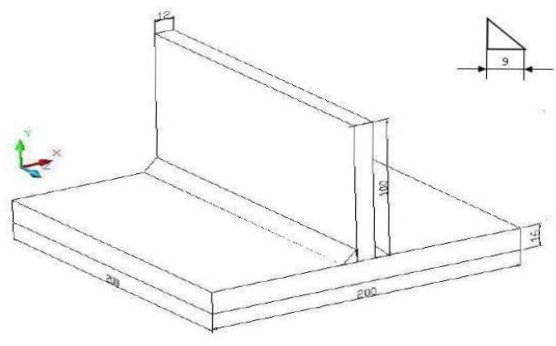

(a)

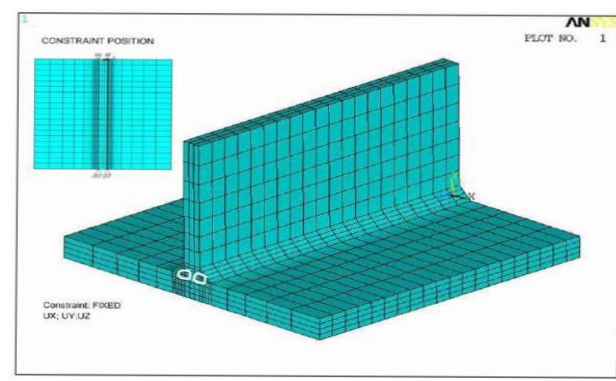

(b)

Figure 9. (a) Geometry of T-joint fillet welds, (b) Mesh of T-joint fillet weld along with its constraint position. 


\section{Results and discussion}

With the finite element procedures described in the previous section, results on the problem considered are presented in this section. The finite element simulation for all the variation of welding was completed in 45 load-steps (LS). During the number of load-steps, the welding process took for 40 load-steps, while the cooling one took for the rest of the LS. For the presentation of welding simulation, the results of the LS which respectively represent the conditions of the peak temperature and the beginning of cooling processes were taken and plotted. Note that the temperature went down towards the reference (room) temperature after the LS of 41. Accordingly, the longitudinal and transverse residual stresses and the distortions occurred due to the welding sequences were presented and discussed.

\subsection{Welding simulations and temperature distributions}

First, thermal profile produced during welding as the heat source travels is presented as shown in Fig. 10. Fig. 10 represents the thermal profiles on several selected nodes along one fillet weld taken from WS-1 simulation results. It was shown that heat was moving as the welding heat source travelled. This can also be seen from the high temperature of the next adjacent node when the previous node has achieved its peak temperature. In addition, the next adjacent node's peak temperature was higher than that of the previous one, which also indicated that heat was accumulated. Subsequently, it has been distributed through the welding structure and the heat release to the surroundings was due to convective heat transfer.

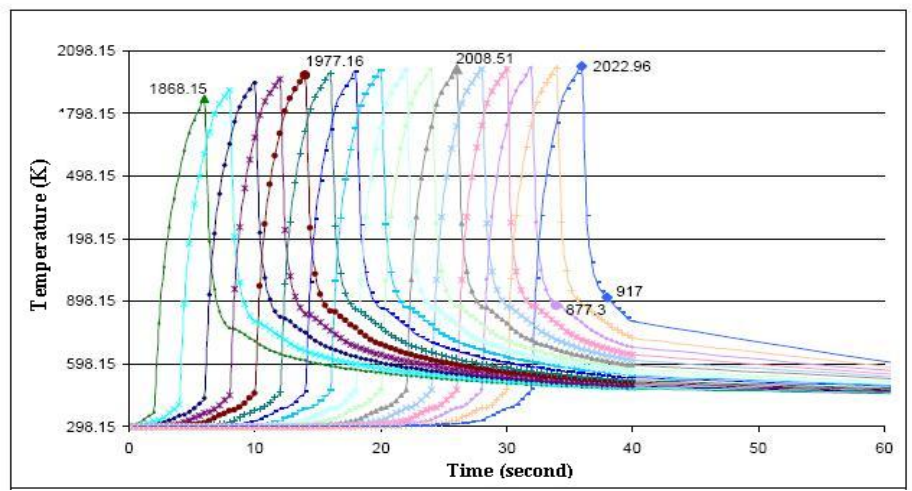

Figure 10. Thermal profiles on several selected nodes along the fillet weld.

Figs. 11 - 14 illustrate the welding simulation showing the peak temperature for each welding sequence and the temperature distribution after welding towards the room temperature. From the temperature distributions, it is clear that the peak temperature achieved in the welding was greatly affected by the welding sequence. The welding sequences produced different interaction between the current step and the accumulation of heat carried out from the previous steps due to the sequential path followed. 


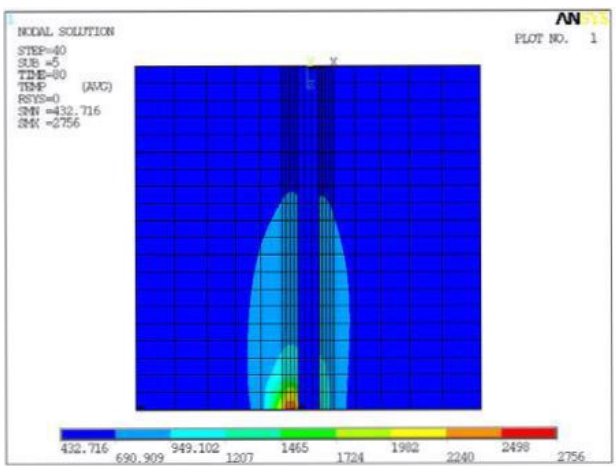

(a)

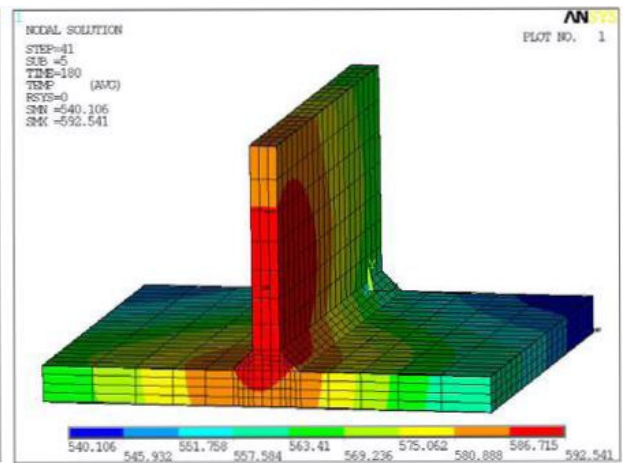

(b)

Figure 11. The welding simulation for WS-1: (a) the peak temperature achieved at the LS of 40, and (b) the temperature distribution after the welding process at the LS of 41 .

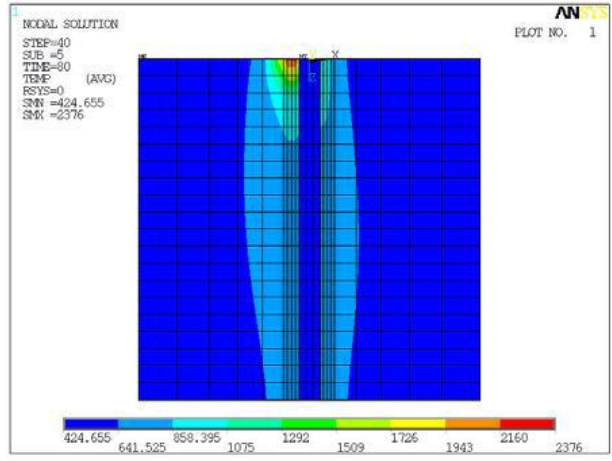

(a)

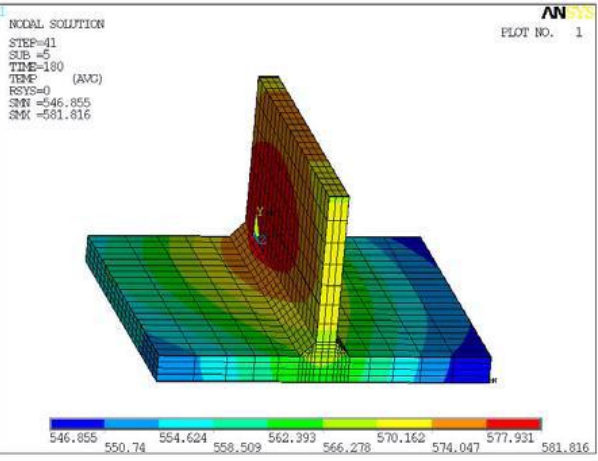

(b)

Figure 12. The welding simulation for WS-2: (a) the peak temperature achieved at the LS of 40, and (b) the temperature distribution after the welding process at the LS of 41.

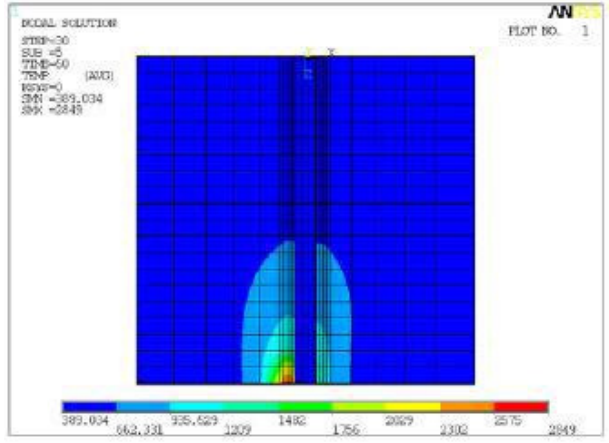

(a)

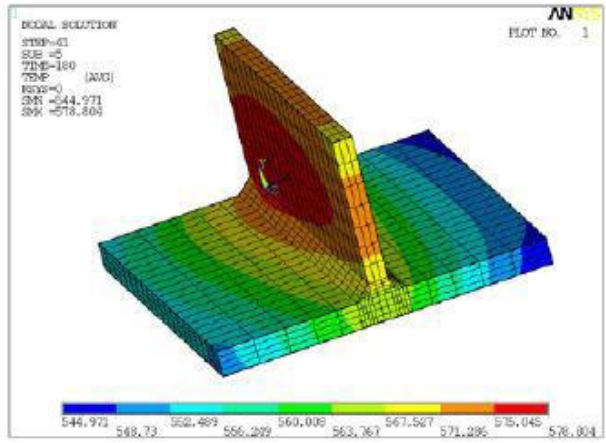

(b)

Figure 13. The welding simulation for WS-3: (a) the peak temperature achieved at the LS of 30, and (b) the temperature distribution after the welding process at the LS of 41. 


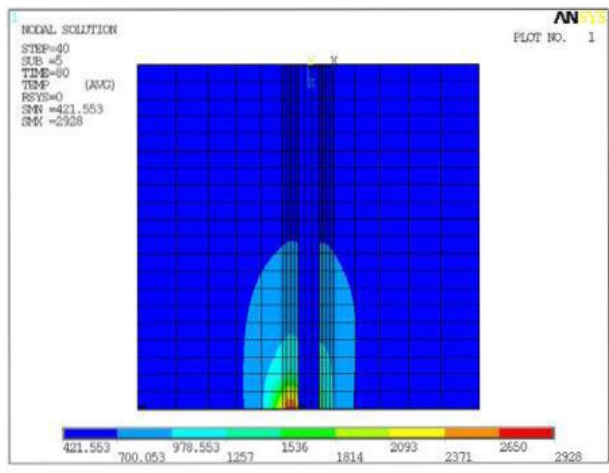

(a)

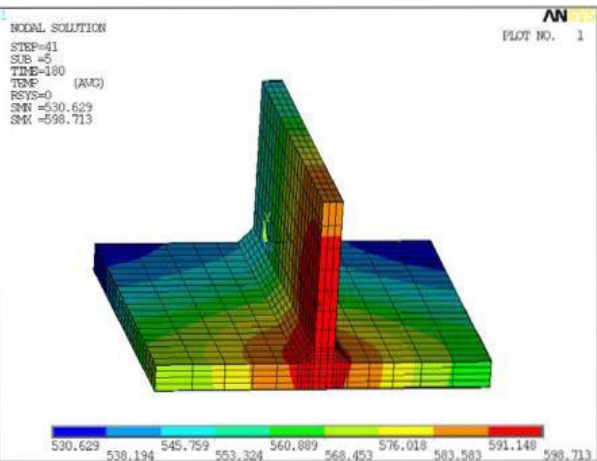

Figure 14. The welding simulation for WS-4: (a) the peak temperature achieved at the LS of 40 , and (b) the temperature distribution after the welding process at the LS of 41.

The peak temperature achieved for each welding sequence as well as the peak temperature difference between WS were summarized in Table 1, in which the highest peak temperature of $2928 \mathrm{~K}$ belongs to WS-4 having the highest heat accumulation at the end of the welding process. The shapes of the temperature profile at the fillet welds during welding were depicted in Fig. 15.

From Fig. 15, it can be seen the differences of the temperature profile at the fillet welds during different WS. It is interesting to note that in general the temperature profiles of WS-1 and WS- 2 tend to be similar. In a less extent, it also happened for those of WS-3 and WS-4, as the peak temperature of WS-3 was achieved at the LS of 30. Nevertheless, the peak temperature achieved was very different, even for the WS having similar temperature profiles such as WS-1 and WS-2. This verified again that the peak temperature achieved in the welding was greatly affected by the welding sequence.

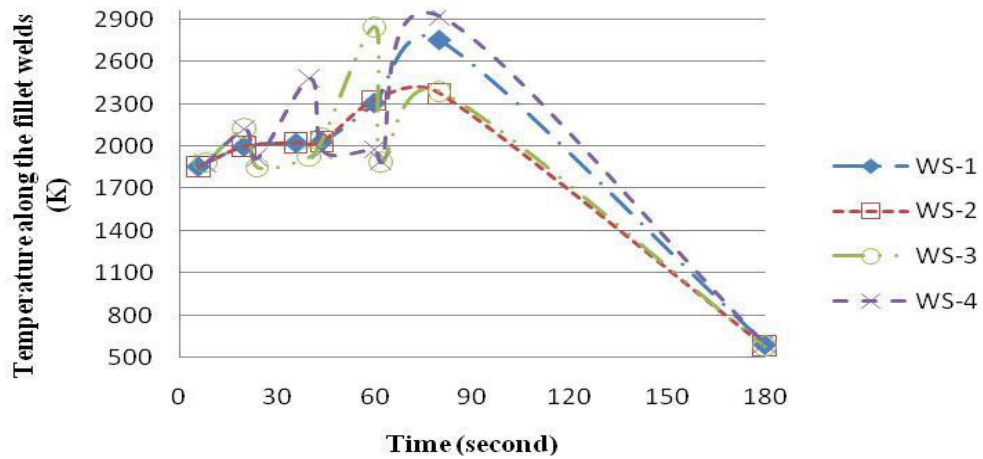

Figure 15. Peak temperature for each welding sequence. 
Table 1 describes further the peak temperature achieved in a WS and the peak temperature difference between WS, in which the smallest and largest peak temperature differences between WS were 79 and $552 \mathrm{~K}$, respectively.

Moreover, it may be also interesting to note how the peak temperature achieved in a WS may be related to the corresponding residual stresses and angular distortions produced.

\begin{tabular}{|c|c|c|c|}
\hline $\begin{array}{c}\text { Welding sequence } \\
\text { (WS) }\end{array}$ & $\begin{array}{c}\text { Load-step } \\
\text { (LS) }\end{array}$ & $\begin{array}{c}\text { The peak temperature } \\
\text { achieved [K] }\end{array}$ & $\begin{array}{c}\text { The peak temperature } \\
\text { difference between WS [K] }\end{array}$ \\
\hline 4 & 40 & 2928 & - \\
\hline 3 & 30 & 2849 & 79 \\
\hline 1 & 40 & 2756 & 380 \\
\hline 2 & 40 & 2376 & 93 \\
\hline
\end{tabular}

Table 1. The peak temperature achieved for each welding sequence.

\section{2. Residual stress distributions}

Fig. 16 and 17 shows respectively the simulated distributions of longitudinal and transverse residual stresses for each welding sequence investigated in this study. It is seen from Fig. 16 and 17, the maximum values of the longitudinal and transverse residual stresses occurred in the weld bead region for all the welding sequences. Note also that the distribution of the residual stresses produced from each of the welding sequences.

It can be seen that the smallest longitudinal and transverse residual stresses occurred in WS-2. It is interesting to note that the welding sequence also had the lowest peak temperature as indicated in Table 1. Also, for longitudinal residual stresses, their distributions due to the welding sequences tend to be similar. For transverse ones, the distributions were different. It seems that for the later, it could be related to the way of the welding had been performed.

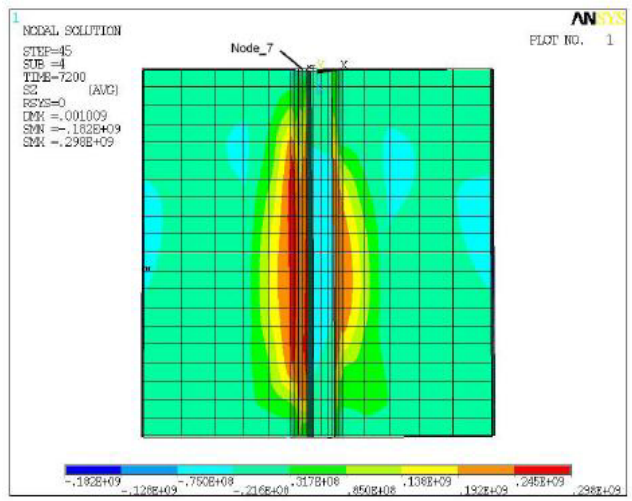

(a)

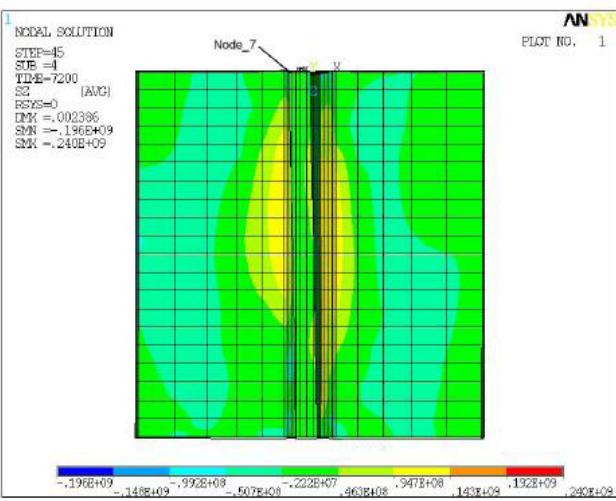

(b) 


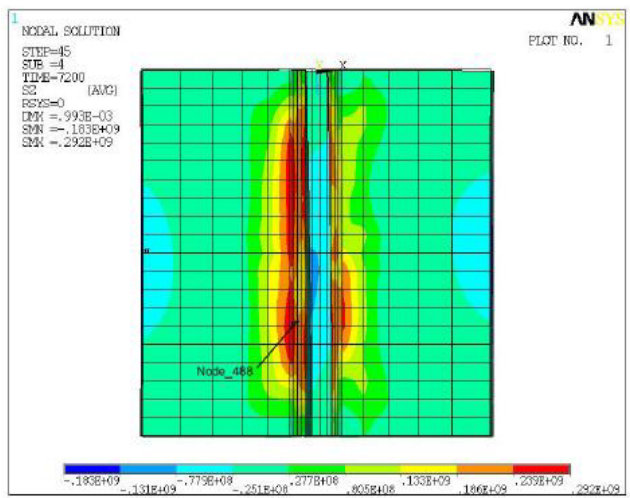

(c)

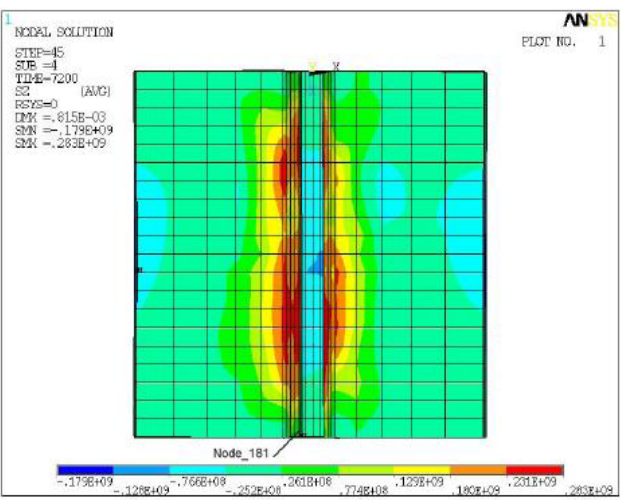

(d)

Figure 16. Simulated distributions of longitudinal residual stresses for: (a) WS-1, (b) WS-2, (c) WS-3, and (d) WS-4.

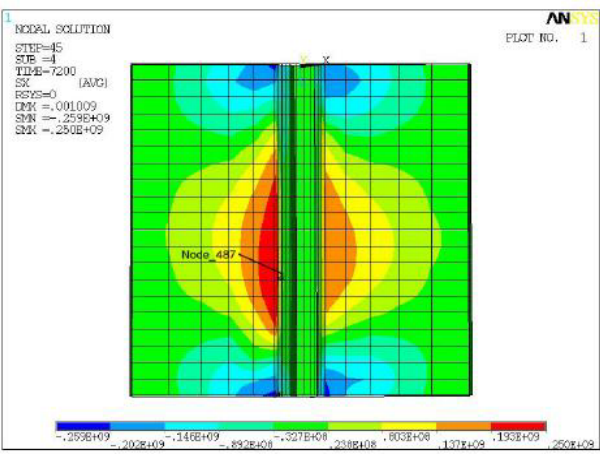

(a)

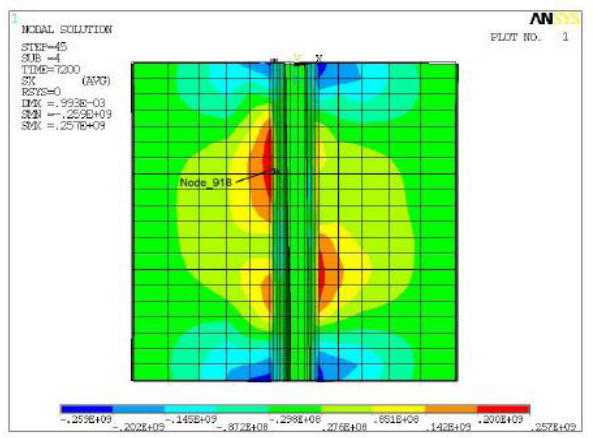

(c)

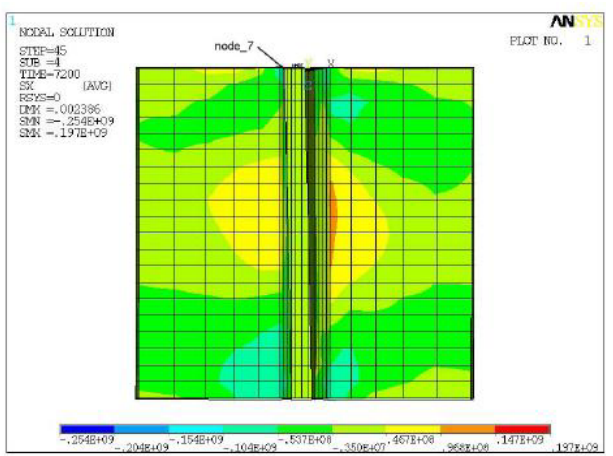

(b)

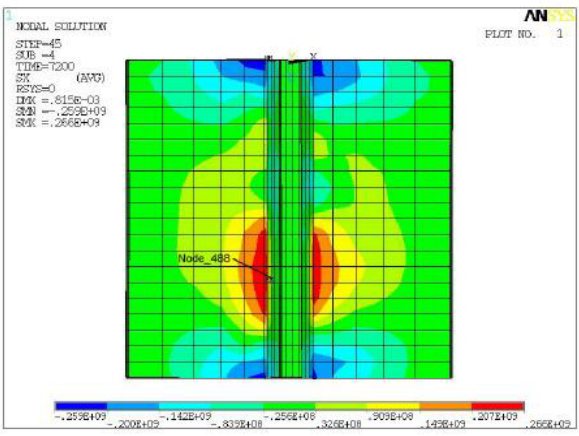

(d)

Figure 17. Simulated distributions of transverse residual stresses for: (a) WS-1, (b) WS-2, (c) WS-3, and (d) WS-4. 
Fig. 18 describes the transverse residual stress distribution along the fillet weld for each WS. The maximum values of longitudinal and transverse stresses as well as von Mises stress for each welding sequence were summarized in Table 2 . The ratio between the longitudinal and the transverse residual stress values for the problem considered varies from 1. 06 to 1. 22 .

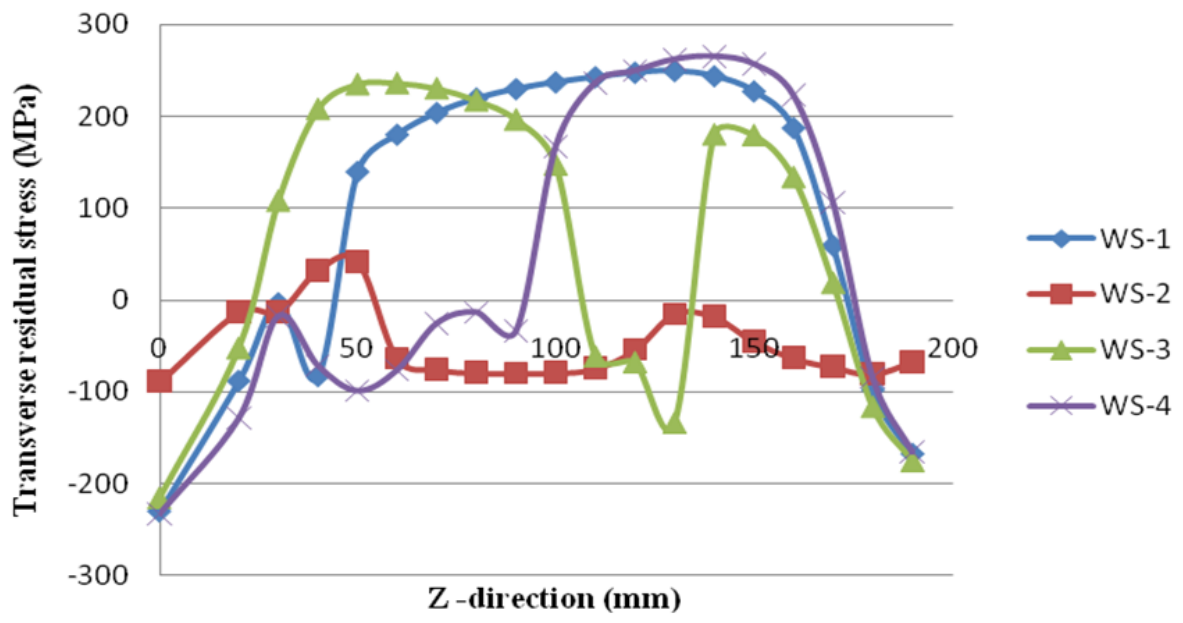

Figure 18. Distribution of transverse residual stress along the fillet weld for each welding sequence.

Observing further Fig. 18, it is also interesting to note the consistency of trends of the transverse residual stresses distributions produced by the WS simulated in the present study. It can be clearly observed that the distributions of transverse residual stresses produced by WS-3 and WS-4 and WS-1 and WS-2, respectively, are in consistent nature with respect to the welding sequences.

\begin{tabular}{|c|c|c|c|}
\hline $\begin{array}{c}\text { Welding sequence } \\
\text { (WS) }\end{array}$ & $\begin{array}{c}\text { The maximum longitudinal stress } \\
\text { value [MPa] }\end{array}$ & $\begin{array}{c}\text { The maximum } \\
\text { transverse stress value } \\
{[\mathrm{MPa}]}\end{array}$ & $\begin{array}{c}\text { The maximum } \\
\text { von Mises stress value } \\
{[\mathrm{MPa}]}\end{array}$ \\
\hline 2 & 240 & 197 & 117 \\
\hline 4 & 283 & 266 & 251 \\
\hline 3 & 292 & 257 & 249 \\
\hline 1 & 298 & 250 & 250 \\
\hline
\end{tabular}

Table 2. The maximum longitudinal and transverse stress values for each welding sequence. 


\subsection{Distortions}

Fig. 19 illustrates the distortions of the welding structure due to the welding sequences. The initial undeformed configurations were also shown. From Fig. 19, it can be seen the angular distortions occurred in both flanges. It can be further revealed that there was the difference of distortion between the flanges showing that the distortion was unsymmetrical. The maximum value of angular distortion took place on the right flange for all the welding sequences, unless that of WS-2 which took place on the left one. The simulation results obtained also clearly indicate the influence of the welding sequences examined in the present study to the angular distortions of the T-joint fillet weld considering the same boundary conditions appliedin the corresponding FEM models of the T-joint fillet weld.

Furthermore, Table 3 summarizes the vertical displacements and the angular distortions of both flanges due to the welding sequences. The angular distortion differences were also shown in Table 3.
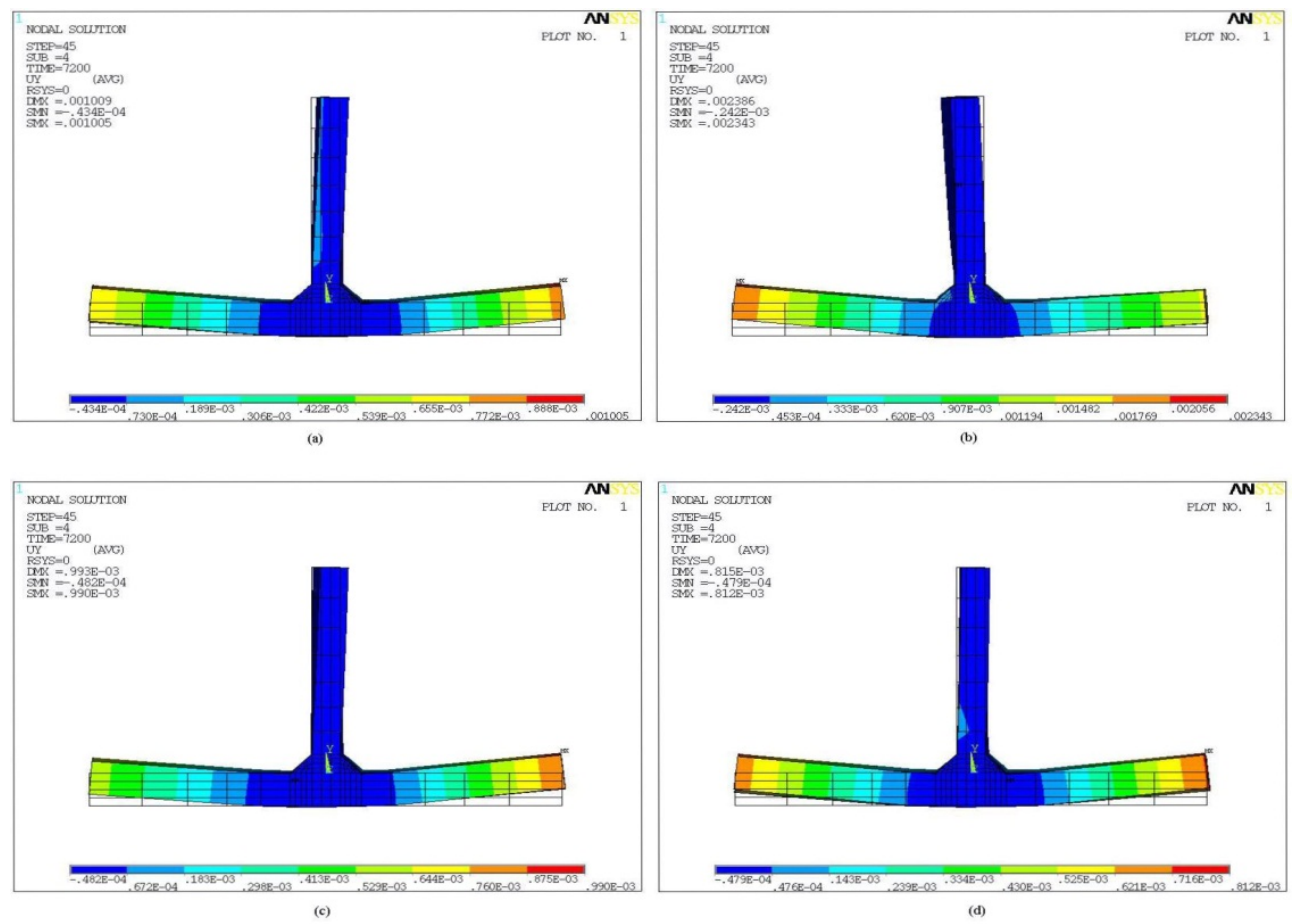

Figure 19. Distortions of the welding structure due to the welding sequences: (a) WS-1, (b) WS-2, (c) WS-3, and (d) WS-4. 


\begin{tabular}{|c|c|c|c|c|c|}
\hline \multirow[b]{2}{*}{ Welding sequence (WS) } & \multicolumn{2}{|c|}{$\begin{array}{l}\text { The left flange } \\
(X=-100 \mathrm{~mm})\end{array}$} & \multicolumn{2}{|c|}{$\begin{array}{l}\text { The right flange } \\
(X=100 \mathrm{~mm})\end{array}$} & \multirow[b]{2}{*}{$\begin{array}{c}\text { Angular distortion } \\
\text { difference } \\
\text { [rad }]\end{array}$} \\
\hline & Uy $[\mathrm{mm}]$ & $\begin{array}{c}\text { Angular } \\
\text { distortion } \\
\text { [rad] }\end{array}$ & Uy $[\mathrm{mm}]$ & $\begin{array}{c}\text { Angular } \\
\text { distortion } \\
\text { [rad] }\end{array}$ & \\
\hline 1 & 0.897 & 0.0090 & 1.005 & 0.0101 & 0.0011 \\
\hline 3 & 0.755 & 0.0076 & 0.990 & 0.0099 & 0.0023 \\
\hline 2 & 2.344 & 0.0240 & 0.897 & 0.0090 & 0.0150 \\
\hline 4 & 0.783 & 0.0078 & 0.812 & 0.0081 & 0.0003 \\
\hline
\end{tabular}

Table 3. The vertical displacements and the angular distortions of both flanges due to the WS.

\subsection{Discussions and recommendation for further research}

From the results, it seems that, for the problem considered in this numerical study, two welding sequences, namely WS-2 and WS-4, have taken the attention. The WS-2, which is called as simple alternating welding, has produced the lowest peak temperature and the smallest longitudinal and transverse residual stresses as well. Meanwhile the WS-4, which is called as multiple crossing welding, has produced the smallest angular distortion and angular distortion difference, although it produced the highest peak temperature.

The information appears to be consistent with respect to the welding sequences performed. The corresponding value of the von Mises stress and the distortion difference produced as shown respectively in Table 2 and 3 indicated this as well. In particular, the results were also in contrast to those of WS-1 and WS-3. Not only did the welding sequences produce high angular distortions, but also they resulted in relatively high values of the von Mises stresses. Furthermore, the distortion results obtained appears to be match with the ones usually found in the welding practice incorporating alternating welding.

Also, considering limited literatures concerning welding simulation of T-joint fillet welds in 3D (Chang \& Lee, 2009 and Deng et al., 2007), the results obtained would be very valuable 
and useful to welding designers and practitioners, because the results have been describing the predicted or anticipated residual stresses and distortions with respect to the welding sequences, varied from simple to multiple crossing welding. In addition, the assessment of welding performance which can be taken in an efficient and fast manner allows the designers to integrate it in their subsequent design plans.

Furthermore, the 3D simulation results of T-joint fillet weld may be further used as validation model for 3D welding simulations as well as for other numerical technique implementations such as mesh-less techniques, where no predefined mesh is required to build interpolation of the potential field variables investigated thus reducing cumbersome mesh preparation and increasing the related simulation time.

Moreover, the relationship between the input and output variables of the welding process may be further investigated and optimized using techniques from artificial intelligence (AI) family, such as neural networks and genetic algorithm. For examples, in the single pass GTAW welding method presented in this study, the variables of welding current, voltage, welding speed and welding sequences have been examined, in which more output variables may be also examined, such as the nature and dimensions of weld bead. Thus, much more information and insights can be revealed in such a welding process, which is in turn very useful to optimize the welding process.

It is noted here that the aspects of shrinkage were not discussed in the present paper. The aspects could be also related to the variation of welding speed. Also, it may be interesting if some welding paths in one WS are performed and simulated simultaneously thus allowing the exploitation of symmetry and anti-symmetry boundary conditions in the finite element model. The aforementioned aspects would be the subjects of further investigations.

\section{Conclusions}

Welding sequences effect on temperature distribution, residual stresses and distortions of T-joint fillet welds has been studied numerically in this paper. The simulation results revealed that peak temperature achieved in the welding was greatly affected by the WS and residual stress and angular distortion produced cannot both hold in minimum for a WS. The smallest longitudinal and transverse residual stresses occurred in WS-2, while the smallest angular distortion and difference in WS-4. The distributions of temperature, longitudinal and transverse residual stresses as well as angular distortions were also presented.

Investigating the aspects of shrinkage and simultaneous welding as well as the implementations of other related numerical techniques for further and better understanding of the welding process and its optimization would be the subjects of further publication in the future time. 


\section{Author details}

Nur Syahroni

Department of Ocean Engineering, Institut Teknologi Sepuluh Nopember (ITS),

Surabaya, Indonesia

Mas Irfan Purbawanto Hidayat

Department of Materials and Metallurgical Engineering, Institut Teknologi Sepuluh Nopember

(ITS), Surabaya, Indonesia

\section{Acknowledgement}

Funding provided by Institut Teknologi Sepuluh Nopember (ITS) Surabaya is gratefully acknowledged.

\section{References}

ASM (1990). Metals Handbook Vol. 1, 10th ed. , Properties and Selection: Irons, Steels, and High-Performance Alloys, ASM International USA.

Bathe, K. J. (1996). Finite Element Procedures, Prentice Hall, Inc. , New Jersey.

Bette (1999). Fabrication, Applications Engineering, in: The Welding Engineer's Current Knowledge ed. 2000, EWE-3/4. 12 pp. 8-11, SLV Duisburg Gmbh, Germany.

Chang, K. H. \& Lee, C. H. (2009). Finite Element Analysis of the Residual Stresses in T-joint Fillet Welds Made of Similar and Dissimilar Steels, Int. J. Adv. Manuf. Technol. , Vol. 41, 250-258.

Deng, D. , Murakawa, H. \& Liang, Wei (2007). Numerical Simulation of Welding Distortion in Large Structures, Comput. Methods Appl. Mech. Eng. , Vol. 196, 4613-4627.

Goldak, J. A. \& Akhlaghi, M. (2005). Computational Welding Mechanics, Springer, Inc. , New York.

Grong, O. (1994). Metallurgical Modelling of Welding, The Institute of Materials, Cambridge.

Lindgren, L. E. (2006). Numerical Modelling of Welding, Comput. Methods Appl. Mech. Eng. , Vol. 195, 6710-6736.

Masubuchi, K. (1980). Analysis of Welded Structures: Residual Stress, Distortion, and their Concequences, Pergamon Press Ltd, London.

Teng, T. L. \& Lin, C. C. (1998). Effect of Welding Conditions on Residual Stresses due to Butt Welds, International Journal of Pressure Vessels and Piping, Vol. 75, 857-864.

Teng, T. L. , Fung, C. P. , Chang, P. H. \& Yang, W. C. (2001). Analysis of Residual Stresses and Distortions in T-joint Fillet Welds, International Journal of Pressure Vessels and Piping, Vol. 78, 523-538.

Teng, T. L. , Chang, P. H. \& Tseng, W. C. (2003). Effect of Welding Sequences on Residual Stresses, Computers and Structures, Vol. 81, 273-286. 
Tsai, C. L. , Park, S. C. \& Cheng, W. T. (1999). Welding Distortion of a Thin-Plate Panel Structure, Welding Research Supplement, 156-165.

Zacharia, T. , Vitek, J. M. , Goldak, J. A. , DebRoy, T. A. , Rappaz, M. \& Bhadeshia, H. K. D. H. (1995). Modeling of Fundamental Phenomena in Welds, Modelling Simul. Mater. Sci. Eng. , Vol. 3, 265-288. 